\title{
ANTICORPOS NEUTRALIZANTES CONTRA O HERPESVÍRUS BOVINO TIPO 1 E O VÍRUS DA DIARREIA VIRAL BOVINA EM BOVINOS VACINADOS E NÃO VACINADOS DA REGIÃO SUL DO ESTADO DO RIO GRANDE DO SUL
}

\author{
BECKER, Alice Silveira ${ }^{1}$; \\ RODRIGUES, Mateus Gonçalves ${ }^{1}$; \\ ORLANDIN, Jéssica Rodrigues ${ }^{1}$; \\ MENEZES, Paulo Quadros de ${ }^{1}$; \\ MATOS, Camila Santos ${ }^{1}$; \\ WILSMANN, Daiane Elisa ${ }^{1}$; \\ VIANA, Aline Ebeling ${ }^{1}$; \\ RODRIGUES, Paulo Ricardo Centeno ${ }^{2}$.
}

Recebido: $11 / 06 / 2015$

Aceito: $21 / 11 / 2015$

${ }^{1}$ Acadêmicos da Faculdade de Veterinária da UFPEL; ${ }^{2}$ Médico Veterinário, Mestre, Técnico Administrativo em Educação, Laboratório de Virologia e Imunologia da Faculdade de Veterinária da UFPEL.

\section{RESUMO}

\begin{abstract}
A Rinotraqueíte Infecciosa Bovina e a Diarréia Viral Bovina são enfermidades virais amplamente distribuídas no mundo e no Brasil, causando graves problemas de ordem reprodutiva, afetando negativamente a produtividade dos rebanhos. $O$ objetivo deste trabalho foi apresentar os resultados dos exames sorológicos realizados pelo Laboratório de Virologia e Imunologia da Faculdade de Veterinária da Universidade Federal de Pelotas entre os anos de 2013 e 2014, na área de bovinocultura de corte e leite. Um total de 2303 amostras de soro bovino foram submetidas à técnica de soroneutralização para a deteç̧ão de anticorpos específicos contra o herpesvírus bovino tipo 1 (BoHV-1) e o vírus da Diarréia Viral Bovina (BVDV) de animais vacinados e não vacinados contra esses agentes. Os resultados demonstraram a necessidade do estabelecimento de uma política de defesa sanitária específica, que contemple, além do controle das enfermidades por eles transmitidas, critérios rigorosos para o licenciamento de vacinas no Brasil.
\end{abstract}

Palavras-chave: Doenças reprodutivas. IBR/IPV. BVD. 


\section{INTRODUÇÃO}

O herpesvírus bovino tipo 1 (BoHV-1), responsável pela Rinotraqueíte Infecciosa Bovina (IBR), é um vírus pertencente à família Herpesviridae, subfamília Alfaherpesviridae, do gênero Varicellovirus. A doença, que afeta bovinos jovens e adultos mundialmente, é também conhecida como Vulvovaginite Pustular Infecciosa (IPV) ou Balanopostite Pustular Infecciosa (IPB), forma reprodutiva que acomete tanto fêmeas quanto machos, respectivamente (FRANCO et al., 2012). A transmissão ocorre principalmente por contato direto com secreções contaminadas, incluindo o sêmen (FINO et al., 2012). Mesmo apresentando ocorrências em todo o Brasil, a doença tem sua avaliação epidemiológica dificultada, devido à capacidade viral de permanecer em latência nos gânglios nervosos do animal afetado, sem que este demonstre nenhum sinal clínico (FRANCO et al., 2012).

O agente penetra no organismo pela via respiratória ou genital, invade as células epiteliais locais e realiza seu ciclo de replicação lítica, que culmina com a lise celular. Posteriormente, penetra nas terminações nervosas de nervos sensoriais e migra aos corpos neuronais de gânglios regionais, onde irá permanecer em sua forma latente. Quando sofre ação de estímulos externos, o vírus sai de sua forma de latência e sofre um segundo ciclo replicativo, que será seguido de uma migração de volta ao seu local de origem, onde ocorreu a infecção primária (FRANCO et al., 2012).

A doença causa sinais clínicos como febre, apatia, anorexia, mucosa nasal hiperêmica e com descarga serosa ou mucopurulenta, tosse e dispnéia. Na sua forma reprodutiva, pode gerar orquite em machos e endometrite em fêmeas, além de abortos, bezerros fracos e malformações fetais, quando atinge fêmeas em fase de gestação (MUYLKENS et al., 2007).

O diagnóstico de eleição é o isolamento viral em cultivo celular e identificação através da imunofluorescência utilizando materiais como secreção da mucosa nasal, ocular ou genital. A prevenção se dá através da vacinação do rebanho (PIOVESAN et al., 2013).

A Diarréia Viral Bovina (BVD) e a Doença das Mucosas (DM) são duas doenças de etiologia viral, ambas causadas pelo vírus da Diarréia Viral Bovina (BVDV), que pertence à família Flaviviridae e ao gênero Pestivirus. Este agente acomete diversos ruminantes, especialmente 
bovinos em países onde a bovinocultura de corte e de leite é economicamente relevante (PIOVESAN et al., 2013).

A infecção inicial pelo BVDV utiliza a via oro-nasal, principalmente através de secreções contaminadas de animais persistentemente infectados (PI) (DIAS; SÂMARA, 2010). Seu curso é definido pela influência de alguns fatores, como o status imunológico e reprodutivo do hospedeiro. Em animais não prenhes, é caracterizada por uma infeç̧ão de ordem respiratória ou digestiva, que acomete principalmente animais acima de seis meses de vida. Por ser um agente imunossupressor, o vírus favorece a infecção por outros patógenos virais ou bacterianos. Já em fêmeas prenhes, a doença irá acometer o feto através da via transplacentária, e suas consequências, que dependerão do estágio gestacional e da cepa do virus, vão desde a reabsorção embrionária ou o aborto até o nascimento de bezerros fracos e de crescimento retardado (FLORES et al., 2005). A Doença das Mucosas, enfermidade que acomete geralmente animais entre seis meses e dois anos de idade, ocorre quando um animal persistentemente infectado (PI) com um BVDV não citopático sofre uma nova infecção por um BVDV citopático antigenicamente semelhante, desencadeando uma doença quase sempre fatal, caracterizada por febre, diarréia e lesões erosivas na mucosa oro-nasal, entre outros sintomas (RIDPATH et al., 2012).

O isolamento do agente em cultivo celular, seguido de identificação por imunofluorescência ou imunoperoxidase são as técnicas preferencialmente utilizadas no dignóstico, pois a grande maioria dos isolados de campo são não citopatogênicos (RIDPATH et al., 2012).

Em países como o Brasil, onde há grande movimentação de animais e a prevalência do BVDV é próxima de $50 \%$, em algumas áreas, a alternativa mais racional de controle deve ser a identificação e eliminação dos animais PI e a vacinação do rebanho (LIMA et al., 2005; RIDPATH et al., 2012).

O objetivo deste trabalho foi apresentar os resultados dos exames sorológicos realizados pelo Laboratório de Virologia e Imunologia da Faculdade de Veterinária da Universidade Federal de Pelotas (Labvir/UFPEL) entre os anos de 2013 e 2014, na área de bovinocultura de corte e leite. 


\section{MATERIAL E MÉTODOS}

Durante os anos de 2013 e 2014 foram colhidas amostras de sangue de 2303 bovinos de raças de corte e leite provenientes de 93 propriedades rurais situadas em 19 municípios da região sul do estado do Rio Grande do Sul. As amostras de sangue foram colhidas através de punção da veia jugular externa com agulhas e tubos descartáveis e estéreis. Os tubos contendo sangue sem anticoagulante foram enviados sob refrigeração ao laboratório para separação do soro. No laboratório as amostras foram centrifugadas durante 15 min. a 2000 rpm. Os soros obtidos foram armazenados em microtubos tipo Eppendorf previamente identificados, colocados em um banho-maria a $56{ }^{\circ} \mathrm{C}$ por $30 \mathrm{~min}$. para inativação do sistema complemento e mantidos $\mathrm{a}-20^{\circ} \mathrm{C}$ para posterior processamento.

A técnica de soroneutralização (SN) para determinação dos títulos de anticorpos neutralizantes contra o BoHV e o BVDV foi realizada conforme descrita por Fischer et al. (2007).

Nos anos de 2013 e 2014 foram processados 4003 exames, sendo 2162 para BoHV e 1841 para BVDV.

\section{RESULTADOS E DISCUSSÃO}

O número de propriedades rurais e de bovinos testados para BoHV e/ou BVDV estão apresentados na Tabela 1.

Tabela 1 - Número de propriedades rurais e de bovinos testados através de soroneutralização para BoHV e/ou BVDV nos anos de 2013 e 2014 no Labvir/UFPEL.

\begin{tabular}{lcc}
\hline & 2013 & 2014 \\
\hline Propriedades rurais & 51 & 42 \\
Número de animais & 1101 & 1202
\end{tabular}

Os resultados da sorologia para o BoHV de animais não vacinados (Tabela 2) mostraram uma taxa de bovinos positivos ao redor de $25 \%$, valor próximo da prevalência média de $29,2 \%$ encontrada por Holz et al. (2009) que estimaram a prevalência de anticorpos contra os herpes bovinos tipos 1 e 5 no estado do Rio Grande do Sul. Nesse estudo foram avaliados 
por SN 2200 soros bovinos não vacinados provenientes de 390 propriedades de 158 municípios, a mesorregião Sudeste, a mesma região de atuação do Labvir/UFPEL, apresentou uma prevalência média de $28,1 \%$.

Tabela 2 - Resultados obtidos através de soroneutralização de amostras de bovinos não vacinados contra o BoHV nos anos de 2013 e 2014 no Labvir/UFPEL.

\begin{tabular}{ccccc}
\hline & $\mathbf{2 0 1 3}$ & \% & $\mathbf{2 0 1 4}$ & \% \\
\hline Positivos & 186 & 26,4 & 113 & $\mathbf{2 1}$ \\
Negativos & 519 & 73,6 & 406,3 \\
\hline Total & $\mathbf{7 0 5}$ & $\mathbf{1 0 0}$ & $\mathbf{5 1 9}$ & $\mathbf{1 0 0}$ \\
\hline
\end{tabular}

Dos animais não vacinados com sorologia positiva contra o herpes bovino, 54,8\% e 49,6\% apresentaram títulos baixos ( $\leq 8$ ), 40,9\% e 39,8\% títulos médios (entre 16 e 64) e 4,3\% e 10,6\% títulos altos ( $\geq 128$ ) em 2013 e 2014, respectivamente (Tabela 3).

Tabela 3 - Títulos encontrados através de soroneutralização de amostras de bovinos não vacinados contra o BoHV nos anos de 2013 e 2014 no Labvir/UFPEL.

\begin{tabular}{ccccc}
\hline Título & $\mathbf{2 0 1 3}$ & $\%$ & $\mathbf{2 0 1 4}$ & $\%$ \\
\hline 2 & 35 & 18,8 & 9 & 23,0 \\
8 & 30 & 16,1 & 26 & 18,6 \\
16 & 37 & 19,9 & 21 & 15,0 \\
32 & 32 & 17,2 & 17 & 16,8 \\
64 & 31 & 16,7 & 19 & 8,0 \\
128 & 13 & 7,0 & 9 & 8,0 \\
$\geq 256$ & 6 & 3,2 & 9 & 2,6 \\
\hline Total & 2 & 1,1 & 3 & $\mathbf{1 0 0}$ \\
\hline
\end{tabular}

Na Tabela 4 estão apresentados os resultados sorológicos obtidos dos animais vacinados contra o herpes bovino com produtos de diferentes empresas e variados períodos pós vacinais. Em 2014, podemos observar que os animais testados apresentaram uma 
soropositividade menor (72,9\%) quando comparados com os valores obtidos em 2013 $(83,8 \%)$.

Tabela 4 - Resultados obtidos através de soroneutralização de amostras de bovinos vacinados contra o BoHV nos anos de 2013 e 2014 no Labvir/UFPEL.

\begin{tabular}{ccccc}
\hline & $\mathbf{2 0 1 3}$ & \% & $\mathbf{2 0 1 4}$ & \% \\
\hline Positivos & 332 & 83,8 & 395 & 72,9 \\
Negativos & 64 & 16,2 & 147 & 27,1 \\
\hline Total & 396 & $\mathbf{1 0 0}$ & $\mathbf{5 4 2}$ & $\mathbf{1 0 0}$ \\
\hline
\end{tabular}

Dos animais vacinados com sorologia positiva contra o herpes bovino, $40,7 \%$ e $41,3 \%$ apresentaram títulos baixos ( $\leq 8), 48,5 \%$ e $47,1 \%$ títulos médios (entre 16 e 64 ) e 10,8\% e 11,6\% títulos altos ( $\geq 128$ ) em 2013 e 2014, respectivamente (Tabela 5).

Segundo Radostits et al. (2007 apud BACCILI, 2013), para o BoHV títulos menores que 32 não são protetores. Com isso, temos que 58,2\% em 2013 e 62,8\% em 2014, dos bovinos vacinados contra o BoHV e avaliados não estavam protegidos contra esse agente. Se considerarmos, também, os animais que mesmo vacinados não apresentaram títulos, esses valores aumentam para 64,9\% em 2013 e 72,9\% em 2014.

Tabela 5 - Títulos encontrados através de soroneutralização de amostras de bovinos vacinados contra o BoHV nos anos de 2013 e 2014 no Labvir/UFPEL.

\begin{tabular}{ccccc}
\hline Título & 2013 & $\%$ & 2014 & $\%$ \\
\hline 2 & 28 & 8,4 & 37 & 9,4 \\
4 & 51 & 15,4 & 57 & 17,5 \\
8 & 56 & 16,9 & 69 & 21,5 \\
16 & 58 & 17,5 & 85 & 14,7 \\
64 & 66 & 19,9 & 58 & 10,9 \\
128 & 37 & 11,1 & 43 & 7,3 \\
$\geq 256$ & 19 & 5,7 & 29 & 4,3 \\
\hline Total & 17 & 5,1 & 17 & $\mathbf{1 0 0}$ \\
\hline
\end{tabular}


Os resultados da sorologia para o BVDV de animais não vacinados (Tabela 6) mostraram uma taxa de positivos ao redor de 55\%, valor próximo do encontrado por Vidor (2004 apud Flores et al., 2005), que relatou uma taxa de soropositividade de 58,8\% ao analisar por SN 697 bovinos provenientes de 47 propriedades rurais de 17 municípios da metade sul do estado do Rio Grande do Sul, assim como o estudo realizado por Weiblen (2004 apud Flores et al., 2005), que encontrou soropositividade de 39,3\% ao testar por SN 14535 bovinos procedentes de 1264 propriedades rurais do mesmo Estado.

Tabela 6 - Resultados obtidos através de soroneutralização de amostras de bovinos não vacinados contra o BVDV nos anos de 2013 e 2014 no Labvir/UFPEL.

\begin{tabular}{ccccc} 
& $\mathbf{2 0 1 3}$ & \% & $\mathbf{2 0 1 4}$ & \% \\
\hline Positivos & 260 & 56,8 & 319 & 51,0 \\
Negativos & 198 & 43,2 & 306 & 49,0 \\
\hline Total & 458 & 100 & $\mathbf{6 2 5}$ & $\mathbf{1 0 0}$ \\
\hline
\end{tabular}

Dos animais não vacinados com sorologia positiva contra o BVDV, 7,3\% e 19,8\% apresentaram títulos baixos ( $\leq 8), 29,6 \%$ e $39,7 \%$ títulos médios (entre 16 e 64) e 63,1\% e 40,5\% títulos altos ( $\geq 128$ ) em 2013 e 2014, respectivamente (Tabela 7).

Tabela 7 - Títulos encontrados através de soroneutralização de amostras de bovinos não vacinados contra o BVDV nos anos de 2013 e 2014 no Labvir/UFPEL.

\begin{tabular}{ccccc}
\hline Título & $\mathbf{2 0 1 3}$ & \% & $\mathbf{2 0 1 4}$ & $\%$ \\
\hline 2 & 6 & 2,3 & 14 & 4,4 \\
4 & 7 & 2,7 & 19 & 6,0 \\
8 & 6 & 2,3 & 30 & 9,4 \\
16 & 12 & 4,6 & 46 & 14,4 \\
32 & 24 & 9,2 & 33 & 10,3 \\
64 & 41 & 15,8 & 48 & 15,0 \\
128 & 49 & 18,9 & 37 & 11,6 \\
$\geq 256$ & 115 & 44,2 & 92 & 28,9 \\
\hline Total & $\mathbf{2 6 0}$ & $\mathbf{1 0 0}$ & $\mathbf{3 1 9}$ & $\mathbf{1 0 0}$ \\
\hline
\end{tabular}


Na Tabela 8 estão apresentados os resultados sorológicos obtidos dos animais vacinados contra o BVDV com produtos de diferentes empresas e variados períodos pós vacinais. Em 2014 os animais testados apresentaram uma soropositividade menor (59,2\%) quando comparados com os valores obtidos em 2013 (98,3\%).

Tabela 8 - Resultados obtidos através de soroneutralização de amostras de bovinos vacinados contra o BVDV nos anos de 2013 e 2014 no Labvir/UFPEL.

\begin{tabular}{ccccc} 
& $\mathbf{2 0 1 3}$ & \% & $\mathbf{2 0 1 4}$ & \% \\
\hline Positivos & 355 & 98,3 & 235 & 59,2 \\
Negativos & 6 & 1,7 & 162 & 40,8 \\
\hline Total & 361 & 100 & 397 & 100 \\
\hline
\end{tabular}

Dos animais vacinados com sorologia positiva contra o BVDV, 2,3\% e 10,7\% apresentaram títulos baixos ( $\leq 8), 15,4 \%$ e $17,8 \%$ títulos médios (entre 16 e 64 ) e $82,3 \%$ e $71,5 \%$ títulos altos ( $\geq 128$ ) em 2013 e 2014, respectivamente (Tabela 9).

Conforme Ridpath e Bolin (1995 apud BACCILI, 2013) títulos menores que 16 não protegem os bovinos da enfermidade aguda. Consequentemente, 2,3\% em 2013 e 10,7\% em 2014, dos bovinos vacinados contra o BVDV e avaliados não estavam protegidos contra esse agente. Se considerarmos, também, os animais que mesmo vacinados não apresentaram títulos, esses valores aumentam para 3,9\% em 2013 e 47,1\% em 2014. 
Tabela 9 - Títulos encontrados através de soroneutralização de amostras de bovinos vacinados contra o BVDV nos anos de 2013 e 2014 no Labvir/UFPEL.

\begin{tabular}{ccccc}
\hline Título & 2013 & $\%$ & $\mathbf{2 0 1 4}$ & $\%$ \\
\hline 2 & 2 & 0,6 & 9 & 2,6 \\
8 & 1 & 0,3 & 6 & 4,3 \\
16 & 5 & 1,4 & 10 & 4,7 \\
32 & 10 & 2,7 & 11 & 2,1 \\
64 & 12 & 3,4 & 5 & 11,0 \\
128 & 33 & 9,3 & 26 & 13,2 \\
$\geq 256$ & 62 & 17,5 & 31 & 58,3 \\
\hline Total & 230 & 64,8 & 137 & $\mathbf{1 0 0}$ \\
\hline
\end{tabular}

A elevada prevalência do BoHV e do BVDV em bovinos no estado do Rio Grande do Sul e no Brasil somado às perdas econômicas que as enfermidades por eles transmitidas causam à bovinocultura de carne e de leite, revelam a necessidade do estabelecimento de uma política oficial de controle dessas endemias.

Os resultados da sorologia em animais vacinados contra o BoHV e o BVDV, mesmo não sendo uma amostragem estatisticamente relevante, sugerem a possibilidade de estar ocorrendo falha vacinal. Outras investigações devem ser conduzidas nessa área tão importante para a bovinocultura nacional e novos métodos de controle e produção de vacinas comerciais deverão ser implementados. Lima et al. (2005), ao comparar um imunógeno experimental atenuado e três vacinas comerciais inativadas, em suas conclusões, apontaram várias restrições às vacinas comercializadas contra o BVDV e sugeriram novos critérios para o licenciamento de vacinas no Brasil.

\section{CONCLUSÃO}

A presença de anticorpos contra o BoHV e o BVDV, em bovinos não vacinados, na região sul do estado do Rio Grande do Sul é relevante e demonstra a necessidade do estabelecimento de uma política de defesa sanitária específica para esses agentes infecciosos. O número de 
bovinos vacinados e não protegidos contra o BoHV e o BVDV indicam o dever e a urgência da criação de novas regras e critérios para o licenciamento de vacinas para animais em nosso País, e métodos de controle que assegurem proteção aos rebanhos.

\section{NEUTRALIZING ANTIBODIES AGAINST BOVINE HESPERVIRUS TYPE 1 AND BOVINE VIRAL DIARRHEA VIRUS IN VACCINATED AND NON-VACCINATED CATTLE IN THE SOUTH REGION OF RIO GRANDE DO SUL STATE}

\section{ABSTRACT}

I nfectius bovine rhinotracheitis and bovine viral diarrhea are viral diseases widely distributed in the world and in Brazil, causing serious problems of reproductive order, affecting negatively the productivity of herds. The objective of this study was to present the results of serological tests performed by the Laboratory of Virology and Immunology from the Faculty of Veterinary Medicine, Federal University of Pelotas between the years of 2013 and 2014, from beef and dairy cattle. A total of 2303 serum samples were subjected to the seroneutralization test for the detection of specific antibodies against bovine herpesvirus type 1 (BoHV-1) and bovine viral diarrhea virus (BVDV) from vaccinated and non-vaccinated cattle against these agents. The results demonstrated the need to establish a specific health protection policy that includes, beyond the control of the diseases they transmit, strict criteria for the licensing of vaccines in Brazil.

Keywords: Reproductive diseases. IBR/IPV. BVD.

\section{ANTICUERPOS NEUTRALIZANTES CONTRA EL HERPESVIRUS BOVINO DE TIPO 1 $Y$ EL VIRUS DE LA DIARREA VIRAL BOVINA EN EL GANADO VACUNADO Y NO VACUNADO EN LA REGIÓN SUR DEL ESTADO DEL RIO GRANDE DO SUL}

\section{RESUMEN}

a Rinotraqueites Infecciosa Bovina y la Diarrea Viral Bovina son enfermedades virales ampliamente distribuidas en el mundo y en Brasil, causando graves problemas de orden reproductivo, lo que afecta negativamente a la productividad de los rebaños. El objetivo de este trabajo fue presentar los resultados de las pruebas serológicas realizadas por el Laboratorio de Virología e Inmunología de la Facultad de Medicina Veterinaria de la Universidad Federal de Pelotas, entre los años 2013 y 2014, en el área de ganado de carne y 
leche. Un total de 2303 muestras de suero se sometieron a la prueba de neutralización para la detección de anticuerpos específicos contra herpesvirus bovino tipo 1 (BoHV-1) y el virus de la diarrea viral bovina (BVDV) de vacunados y no vacunados contra estos agentes. Los resultados demostraron la necesidad de establecer una política específica de protección de la salud que incluye, fuera del control de las enfermedades que transmiten, criterios estrictos para la concesión de licencias de las vacunas en Brasil.

Palabras clave: Enfermedades de la reproducción. IBR/IPV. BVD.

\section{REFERÊNCIAS}

BACCILI, C. C. Imunização passiva e ativa de bezerros para o vírus da Diarreia Viral Bovina (BVDV) e Herpesvírus Bovino tipo 1 (BoHV-1). São Paulo: FMVZ/USP, 2013, 124p.

Dissertação (Mestrado em Veterinária), Faculdade de Medicina Veterinária e Zootecnia, Universidade de São Paulo, 2013.

DIAS, F. C.; SÂMARA, S. I. Aspectos relevantes da infecção pelo vírus da Diarréia Viral Bovina (BVDV). Biológico, v. 72, n. 1, p. 1-9, jan./jun. 2010. Disponível em: < http://www.biologico.sp.gov.br/docs/bio/v72_1/dias.pdf>.

FINO, T. C. M.; MELO, C. B.; RAMOS, A. F.; LEITE, R. C. Infecções por herpesvírus bovino tipo 1 (BoHV-1) e suas implicações na reprodução bovina. Revista Brasileira de Reprodução Animal, v. 36, n. 2, p. 122-127, abr./jun. 2012.

FISCHER, G.; CONCEIÇÃO, F. R.; LEITE, F. P. L.; DUMMER, L. A.; VARGAS, G. D.; HÜBNER, S. O.; et al. Immunomodulation produced by a green propolis extract on humoral and cellular responses of mice immunized with SuHV-1. Vaccine, n. 25, p. 1250-1256, 2007.

FLORES, E. F.; WEIBLEN, R.; VOGEL, F. S. F.; et al. A infeç̧ão pelo virus da Diarréia Viral Bovina (BVDV) no Brasil - histórico, situação atual e perspectivas. Pesquisa Veterinária Brasileira, v. 25, n. 3, p. 125-134, jul./set. 2005.

FRANCO, A. C.; ROEHE, P. M.; VARELA, A. P. M. Herpesviridae. In: FLORES, E. F. (Org.). Virologia Veterinária. Santa Maria: Editora UFSM, 2012. Cap. 18, p. 503-570.

HOLZ, C. L.; CIBULSKI, S. P.; TEIXEIRA, T. F.; et al. Soroprevalência de herpesvírus bovinos tipos 1 e/ou 5 no Estado do Rio Grande do Sul. Pesquisa Veterinária Brasileira, v. 29, n. 9, p. 767-773, set. 2009.

LIMA, M.; VOGEL, F. S. F.; FLORES, E. F.; WEIBLEN, R. Anticorpos neutralizantes contra o vírus da Diarréia Viral Bovina (BVDV): comparação entre um imunógeno experimental atenuado e três vacinas comerciais inativadas. Ciência Rural, v. 35, n.1 p. 230-234, jan./fev. 2005. 
MUYLKENS, B.; THIRY, J.; KIRTEN, P.; SCHYNTS, F.; THIRY, E. Bovine herpesvirus 1 infection and infectious bovine rhinotracheitis. Veterinary Research, v. 38, n. 2, p. 181-209, mar./abr. 2007.

PIOVESAN, M.; FERNANDES, M. H. V.; CORRÊA, R. A.; PRADO, M. H. J.; CAMARGO, A. D.; RODRIGUES, P. R. C. Anticorpos contra o Herpesvírus bovino tipo 1, vírus da Diarreia Viral Bovina e vírus da Leucose Enzoótica Bovina na região da campanha do estado do Rio Grande do Sul. Science and Animal Health, v. 1, n. 1, p. 38-49, jul./dez. 2013.

RIDPATH, J. F.; BAUERMANN, F. V.; FLORES, E. F. Flaviviridae. In: FLORES, E. F. (Org.).

Virologia Veterinária. Santa Maria: Editora UFSM, 2012. Cap. 23, p. 657-689.

Autor para correspondência: Alice Silveira Becker. Rua Cidade de Évora, 75. Bairro: Recanto de Portugal. Pelotas (RS), CEP 96083-100. asilveirabecker@gmail.com 